\title{
Knowledge of and Attitudes towards Preventive Dental Care among Iranian Dentists
}

\author{
Hadi Ghasemia, DDS \\ Heikki Murtomaab, DDS, PhD, MPH \\ Hassan Torabzadehc, DDS, MSc, PhD \\ Miira M Vehkalahtid, DDS, PhD
}

\begin{abstract}
Objectives: To assess Iranian dentists' knowledge of and attitudes towards preventive dental care.

Methods: A questionnaire survey was conducted at two nationwide annual dental congresses in 2004 and 2005 in Tehran, Iran. Dentists' level of knowledge was assessed based on their responses on a Likert scale (0-4) to nine statements on preventive dental care. Higher scores indicated more accurate knowledge. Dentists' attitudes towards preventive dental care were rated based on responses on a Likert scale (1-7) to nine pairs of bipolar adjectives. The respondents were to choose the response which best described their opinion. Higher scores indicated more positive attitudes. Of 1033 responding dentists, 980 (64\% men) were deemed eligible for this study. Statistical evaluation was by t-test and the Chi-square test.

Results: Highest ratings were obtained for knowledge of the role of sugar consumption (Mean \pm SD: $3.73 \pm 0.60)$, sealants $(3.58 \pm 0.68)$, and water fluoridation $(3.35 \pm 0.81)$ in caries prevention; the lowest for their knowledge of the superiority of the use of fluoride toothpaste over technique of brushing (1.11 \pm 1.09 ). Dentists' attitudes towards preventive dental care appeared most positive regarding its usefulness (Useful - Useless; 6.67 \pm 0.94 ), value (Valuable - Worthless; 6.59 \pm 0.98 ) to the community and for its status as a scientific (Scientific - Unscientific; 6.47 \pm 1.06 ) subject. Overall, female dentists had more favourable attitudes towards preventive dental care than male colleagues.

Conclusions: Preventive dentistry should be emphasised in dental education in order to update dentists' knowledge and attitudes regarding preventive dental care. (Eur J Dent 2007;1:222-229)
\end{abstract}

Key Words: Preventive dentistry; Dental care; Iranian Dentists; Dental Education.

\section{INTRODUCTION}

Dentists' knowledge of and attitudes towards oral health care provide the framework for their

professional work. Since dentists are the persons who convey evidence-based knowledge of oral

- a Research Fellow, Department of Oral Public Health, Institute of Dentistry, University of Helsinki,

b Professor, Head and Chair Department of

Oral Public Health, Institute of Dentistry,

University of Helsinki

Assoc. Professor, Department of Operative Dentistry,

Faculty of Dentistry,

Shaheed Beheshti University of Medical Sciences,

d Adjunct Professor, Senior Researcher,

Dept. of Oral Public Health, Institute of Dentistry,

University of Helsinki

- Corresponding Author: Hadi Ghasemi P.0.B. 41, Department of Oral Public Health, Institute of Dentistry, University of Helsinki, FI-00014 Helsinki, Finland Phone: + 358-9-19127301

Fax: + 358-9-19127346 E-mail: hadi.ghasemidhelsinki.fi 
health care to public, ${ }^{1}$ they also influence their patients' oral health-related behaviour. With the exponential growth of dental science, dentists need to update their practices according to the best available scientific evidences. Dentists' treatment decisions are influenced by their knowledge of and attitudes towards care options, ${ }^{2}$ and assessing these is worthwhile. ${ }^{3}$

Preventive approach in dental practice has been cited as a reason for caries decline in recent decades ${ }^{4}$ and as a predominant part of the service-mix of dental practices in the future. ${ }^{5}$ The reorientation of oral health services towards prevention and health promotion is one of WHO's priority action areas for the continuous improvement of oral health. ${ }^{6}$ The knowledge, attitudes and practices of dental professionals need to follow this reorientation.

Previous studies of dentists' knowledge of and attitudes towards preventive dental care have not produced clear-cut results. Although dentists generally seem to be knowledgeable of preventive matters $^{7}$ and have positive attitudes towards prevention, 8,9 deficiencies in their knowledge have been reported. $1,10,11$ With this background, the present study aimed to evaluate Iranian dentists' knowledge of and attitudes towards preventive dental care in relation to their age, gender, and professional characteristics.

\section{MATERIALS AND METHODS}

The present data were gathered by means of a self-administered questionnaire distributed to Iranian general dental practitioners (GDP) who attended in a major nationwide dental congress in Tehran, Iran, in December 2004 or in July 2005. The respondents filled in the questionnaire, which was included in the congress documents, and returned it anonymously before its conclusion. The survey method is described in greater detail elsewhere. ${ }^{12}$ Background information covered dentist's year of birth, gender, work-related factors, and activity in continuing education.

Assessment of dentists' knowledge of preventive dental care

Nine statements (Table 1) on the prevention of dental caries were drawn from a recent text book $^{13}$ and a doctoral thesis at the University of Helsinki ${ }^{14}$ and adapted for use in an assessment of the respondents' knowledge of preventive dental care. Responses were given on a 5-point Likertscale, later scored on a scale ranging from Fully agree $=4$ to Fully disagree=0; higher scores were for more accurate knowledge. The sum of the scores described the respondent's knowledge of preventive dental care. Those respondents with three or more missing answers were excluded ( $n=23$ ); otherwise, missing answers earned a score of two (midpoint). Based on the distribution of the sum of these scores, three categories were formed: Low (<21), Medium (21-26), and High (2736).

Assessment of dentists' attitudes toward preventive dental care

Using the semantic differential method, ${ }^{15}$ a set of nine pairs of bipolar adjectives which describe preventive dentistry (Table 2) was designed to assess dentists' attitudes towards preventive dental care. The respondents were asked to describe their attitudes towards aspects of preventive dentistry by choosing one option from a Likert-scale, ranging from 1 to 7 ; the higher the score, the more positive the attitudes. The sum of all scores, with a theoretical range of 9-63, served as an indicator of respondents' attitudes towards preventive dental care. Those respondents with three or more missing answers were excluded ( $n=117$ ); otherwise, missing answers earned a score of four (midpoint). Based on the distribution of the sum of these scores, three categories were defined: Low (<46), Medium (46-54), and High (5563).

Work-related factors included location of practice (in Tehran, the capital, or not), years in practice (years since graduation) and practice type, for which answers to the question "What is your current job?" were categorized as: Private solely, Private and Public, or No present clinical work.

Data on dentists' activity in continuing education was obtained by two questions. The first, "When was the last time you attended a continuing education course on caries prevention?", had the response alternatives: Within the last year, 2-5 years ago, More than 5 years ago, Never, and Don't know. Only those who selected first three options were included in the analysis. The second, "Which of the following scientific dental journals do you 
usually read?", had six response alternatives, later dichotomised as Extensive and Non-extensive professional reading, depending on whether the respondent reported having or not having read international scientific dental journals.

\section{Statistical evaluation}

Descriptive statistics included means and standard deviations (SD) of the respondents' knowledge and attitude scores. Statistical significances of the differences between the subgroups to be compared were evaluated using the t-test for mean values and the Chi-square test for frequencies.

\section{RESULTS}

Scores for each of the nine statements on preventive dental care are characterised in Table 1. Dentists' knowledge was most accurate regarding the role of sugar consumption 13.82 for females compared to 3.68 for males; $P<.001$ ) and sealants (no gender difference) in caries prevention,

Table 1. Level of knowledge of preventive dental care among Iranian dentists, assessed by nine statements on a 5-point Likert-scale, later scored as: 0=Fully disagree, 1=Disagree, 2=Don't know, $3=$ Agree, and 4=Fully agree; the greater scores being for higher levels of knowledge.

\begin{tabular}{|c|c|c|c|c|}
\hline \multirow[t]{2}{*}{ Aspects of dentists' knowledge } & $\begin{array}{c}\text { All }^{1} \\
(n=980)\end{array}$ & $\begin{array}{c}\text { Men } \\
(\mathrm{n}=629)\end{array}$ & $\begin{array}{l}\text { Women } \\
(n=351)\end{array}$ & \\
\hline & Mean (SD) & Mean (SD) & Mean (SD) & Pvalue ${ }^{2}$ \\
\hline \multicolumn{5}{|l|}{ Caries-related } \\
\hline $\begin{array}{l}\text { The frequency of sugar consumption plays a } \\
\text { greater role in producing caries than does the } \\
\text { total amount of sugar consumed. }\end{array}$ & $3.73(0.60)$ & $3.68(0.65)$ & $3.82(0.45)$ & $<0.001$ \\
\hline $\begin{array}{l}\text { Sealant is effective in the prevention of pit and } \\
\text { fissure caries in newly-erupted molars. }\end{array}$ & $3.58(0.68)$ & $3.56(0.69)$ & $3.60(0.64)$ & 0.36 \\
\hline $\begin{array}{l}\text { A restored tooth is more likely to be lost than is } \\
\text { a sound one. }\end{array}$ & $2.45(1.31)$ & $2.42(1.32)$ & $2.52(1.28)$ & 0.25 \\
\hline $\begin{array}{l}\text { Examining a newly-erupted tooth with a } \\
\text { sharp explorer will damage enamel rods and } \\
\text { predispose the tooth to caries. }\end{array}$ & $2.10(1.32)$ & $1.99(1.34)$ & $2.29(1.27)$ & 0.001 \\
\hline $\begin{array}{l}\text { A white- or brown-spot lesion that is visible on } \\
\text { a wet tooth surface has penetrated all the way } \\
\text { through the enamel. } \\
\text { Fluoride-related }\end{array}$ & $2.05(1.18)$ & $2.04(1.19)$ & $2.06(1.17)$ & 0.84 \\
\hline $\begin{array}{l}\text { Fluoridation of drinking water in regions with low } \\
\text { fluoride is an effective, safe, and efficient way to } \\
\text { prevent dental caries. }\end{array}$ & $3.35(0.81)$ & $3.37(0.81)$ & $3.32(0.80)$ & 0.32 \\
\hline $\begin{array}{l}\text { Rinsing teeth with less water after tooth brushing } \\
\text { will increase the effect of fluoride that is in the } \\
\text { toothpaste. }\end{array}$ & $2.24(1.20)$ & $2.31(1.19)$ & $2.11(1.21)$ & 0.12 \\
\hline $\begin{array}{l}\text { The use of fluoride toothpaste is more important } \\
\text { than brushing technique in preventing caries. } \\
\text { Relations of dental and general health }\end{array}$ & $1.11(1.09)$ & $1.18(1.13)$ & $1.00(0.99)$ & 0.002 \\
\hline $\begin{array}{l}\text { Having dental problems can lead to general } \\
\text { health problems. }\end{array}$ & $3.00(0.92)$ & $3.06(0.89)$ & $2.90(0.97)$ & 0.008 \\
\hline
\end{tabular}

${ }^{1}$ Cases with three or more missing answers among nine knowledge statements were excluded ( $\mathrm{n}=23$ ); otherwise, missing answers were assigned a score of two (Don't know).

2 Gender difference by means of the t-test.

Sources for the statements: Fejerskov, O. and Kidd, E. A. M. Dental Caries: The Disease and its Clinical Management, pp. 116-213. Oxford: Blackwell Munksgaard, 2003. Tseveenjav B. Preventive dentistry in Mongolia. PhD thesis, University of Helsinki, Finland. Helsinki: Yliopistopaino, 2004. Electronic version: http://ethesis.helsinki.fi/julkaisut/laa/hamma/vk/tseveenjav/ 
followed by the role of water fluoridation in preventing dental caries (no gender difference). The least accurate knowledge concerned the superiority of the use of fluoride toothpaste over brushing technique in dental caries prevention (1.18 for males compared to 1.00 for females; $\mathrm{P}=.002$ ).

Regarding caries-related knowledge, female dentists scored higher than their male colleagues based on age, practice-related factors and activity in continuing education, while male scored higher on fluoride-related knowledge. Male dentists from cities other than the capital scored higher on caries-related knowledge (2.78) than those in the capital (2.68) $(P=.05)$. No other statistically significant differences regarding knowledge scores emerged.

Scores of the dentists' attitudes based on the nine pairs of bipolar adjectives describing preventive dentistry are shown in Table 2. The dentists' attitudes towards preventive dental care were most positive regarding its usefulness (6.67) and value (6.59) to the community, and its status as a scientific subject (6.47). The least positive attitudes were found for some dentist-related aspects, indicating that preventive dentistry was considered to be less economically beneficial
(4.24) and less reputable for dentists (3.90). On five of the nine aspects, female dentists demonstrated significantly more positive attitudes than those of the male dentists.

As to the categories of their level of knowledge of preventive dental care, $22 \%$ of the respondents fell into the high category, $54 \%$ medium and $23 \%$ low. The percentages of the dentists demonstrating a high level of knowledge ranged from 19 to 25 , with no statistically significant difference based on personal and professional background (Table 3).

Of all respondents, $31 \%$ belonged to the high category of positive attitudes towards preventive dental care, while $47 \%$ demonstrated a medium and $22 \%$ a low level of positive attitudes. Table 3 shows the percentages of the dentists scoring high on positive attitudes based on their personal and professional characteristics. Comparisons based on the respondents' backgrounds showed that more women than men belonged to the high category $(39 \%$ vs. $27 \% ; P=.001)$. No other significant difference was found.

\section{DISCUSSION}

The results of the present study showed that the Iranian dentists are generally aware of the effect of sugar, sealants, and water fluoridation

Table 2. Levels of attitudes among Iranian dentists regarding preventive dentistry, assessed by nine pairs ${ }^{1}$ of bipolar adjectives, scored from 1 (indicating the least positive attitude) to 7 (indicating the most positive attitude). Dentists were to choose from the scale the point which best described preventive dentistry.

\begin{tabular}{|c|c|c|c|c|}
\hline \multirow{2}{*}{$\begin{array}{l}\text { Pairs of bipolar adjectives to describe } \\
\text { preventive dentistry }\end{array}$} & $\begin{array}{c}\text { All' } \\
(n=980)\end{array}$ & $\begin{array}{c}\text { Men } \\
(n=629)\end{array}$ & $\begin{array}{l}\text { Women } \\
(n=351)\end{array}$ & \\
\hline & Mean (SD) & Mean (SD) & Mean (SD) & $P$ value ${ }^{2}$ \\
\hline \multicolumn{5}{|l|}{ Community-related attitudes } \\
\hline Useful - Useless to the community & $6.67(0.94)$ & $6.60(1.01)$ & $6.76(0.78)$ & 0.004 \\
\hline Valuable - Worthless to the community & $6.59(0.98)$ & $6.52(1.05)$ & $6.72(0.83)$ & 0.003 \\
\hline \multicolumn{4}{|l|}{ Dentist-related attitudes } & 0.12 \\
\hline Scientific - Unscientific subject & $6.47(1.06)$ & $6.43(1.10)$ & $6.53(0.98)$ & 0.2 \\
\hline Efficient - Not efficient practice for dentists & $6.03(1.33)$ & $5.94(1.40)$ & $6.17(1.20)$ & 0.01 \\
\hline Easy - Difficult for dentists & $5.48(1.76)$ & $5.43(1.77)$ & $5.57(1.74)$ & 0.24 \\
\hline Attractive - Not attractive for dentists & $5.05(1.79)$ & $4.88(1.79)$ & $5.35(1.76)$ & $<0.001$ \\
\hline Beneficial - Costly for dentists & $4.24(1.82)$ & $4.12(1.84)$ & $4.46(1.57)$ & 0.007 \\
\hline Reputable - Disreputable for dentists & 3.90 (1.93) & $3.89(1.90)$ & 3.94 (1.98) & 0.69 \\
\hline
\end{tabular}

${ }^{1}$ Cases with three or more missing answers to the nine attitude items were excluded (n=117); otherwise, missing answers were assigned a score of four (mid point).

${ }^{2}$ Gender difference by means of the t-test. 
on dental caries, but they underestimate the role of fluoridated toothpaste. Their most positive attitudes towards preventive dental care were expressed by describing it as useful and valuable to the community and by considering it to have scientific status. Generally, female dentists demonstrated more positive attitudes towards preventive dental care than did male dentists.

In order for clinical practice to keep pace with dental science, practitioner's knowledge and attitudes towards care options need to improve. ${ }^{2}$
Accurate knowledge will enable dentists to make appropriate decisions on their patients' health. In line with recent findings for Mongolian dentists, ${ }^{14}$ the present results indicate that the majority of Iranian dentists have acquired adequate knowledge regarding the influence of sugar, sealants, and water fluoridation on dental caries and the relationship between dental and general health.

On the other hand, deficiencies were evident in the dentists' knowledge of the role of fluoride

Table 3. Percentages of Iranian dentists' ( $n=980)^{1}$ belonging to the categories of high levels of their knowledge of and attitudes towards preventive dental care, according to their background and professional characteristics.

\begin{tabular}{|c|c|c|c|c|c|}
\hline & & $\begin{array}{l}\text { High level of } \\
\text { knowledge }^{2}\end{array}$ & & $\begin{array}{l}\text { High level } \\
\text { of positive } \\
\text { attitudes }^{3}\end{array}$ & \\
\hline Dentists' characteristics & All & 22 & P value 4 & 31 & $P$ value ${ }^{4}$ \\
\hline \multirow{2}{*}{ Gender } & Men & 22 & \multirow{2}{*}{0.55} & 27 & \multirow{2}{*}{0.001} \\
\hline & Women & 24 & & 39 & \\
\hline \multirow{3}{*}{ Age in years } & $<35$ & 23 & \multirow{3}{*}{0.56} & 32 & \multirow{3}{*}{0.6} \\
\hline & $35-44$ & 22 & & 29 & \\
\hline & $\geq 45$ & 20 & & 35 & \\
\hline \multirow{2}{*}{ Practice location } & Capital & 20 & \multirow{2}{*}{0.14} & 34 & \multirow{2}{*}{0.23} \\
\hline & Non-capital & 25 & & 28 & \\
\hline \multirow{2}{*}{ Practice type } & Private & 22 & \multirow{2}{*}{0.7} & 31 & \multirow{2}{*}{0.9} \\
\hline & Private \& Public & 24 & & 32 & \\
\hline \multirow{3}{*}{ Practice years } & $1-8$ & 23 & \multirow{3}{*}{0.69} & 31 & \multirow{3}{*}{0.73} \\
\hline & $9-16$ & 23 & & 32 & \\
\hline & $\geq 17$ & 19 & & 32 & \\
\hline \multirow{2}{*}{ Professional reading ${ }^{5}$} & Extensive & 21 & \multirow{2}{*}{0.71} & 32 & \multirow{2}{*}{0.71} \\
\hline & Non-extensive & 23 & & 30 & \\
\hline \multirow{3}{*}{$\begin{array}{l}\text { Participation in countinuing } \\
\text { education courses }\end{array}$} & Within last year & 23 & \multirow{3}{*}{0.9} & 33 & \multirow{3}{*}{0.23} \\
\hline & 2-5 years ago & 21 & & 29 & \\
\hline & $>5$ years ago & 25 & & 32 & \\
\hline
\end{tabular}

${ }^{1}$ Those respondents with three or more missing answers were excluded: 23 cases regarding knowledge and 117 cases regarding attitudes.

${ }^{2}$ According to nine statements using a Likert scale with scores 0-4, greater scores for more accurate knowledge. Based on the distribution of the summed scores the respondents were categorised as having a Low (<21), Medium (21-26) or High (27-36) level of knowledge.

${ }^{3}$ According to nine pairs of bipolar adjectives using a Likert scale with scores 1-7, with larger numbers indicating more positive attitudes. Based on the distribution of the summed scores the respondents were categorised as having a Low (<46), Medium (4654) or High (55-63) level of positive attitudes.

${ }^{4}$ Statistical evaluations by means of the Chi-square test, for belonging to the high category.

${ }^{5}$ Extensive reading: reading international scientific dental journals. Non-extensive reading: No reading of international scientific dental journals 
in caries prevention and of some aspects of caries initiation and progression. The dentists in the present study, like Mongolian dentists, ${ }^{14}$ underestimate the role of fluoride in caries prevention in comparison to brushing technique. This is contrary to the opinion of a group of experts ${ }^{16}$ that fluoride plays an important role in caries prevention. Furthermore, new recommendations suggest that rinsing after brushing should be minimised so that teeth can maximally benefit from the fluoride in toothpaste. ${ }^{17}$ Unfortunately, some Iranian dentists may be unaware of the importance of this simple and useful oral health message. Similar deficiencies in this respect have recently been reported for Iranian dental students $^{18}$ and Iranian dental educators. ${ }^{19}$ These may stem from the lack of attention paid to the role of fluoride in caries prevention and cariology in dental education, which is calling for putting more emphasis on these two important subjects in dental curricula and in continuing education.

Post-graduate education, if provided properly, has been stated to increase dentists' knowledge. ${ }^{2}$ Dentist's knowledge of preventive dental care has been shown to diminish as time passes after graduation. ${ }^{1,11}$ This suggests a need for appropriate continuing education programmes. However, activity in continuing education had no impact on dentist's knowledge either for the Mongolian dentists ${ }^{14}$ or for the dentists in this study, probably due to poor content or method of delivery.

The diversity of dentists' knowledge of preventive dental care may be due to differences in the general approach to the management of dental diseases in different countries. The dentists in this study, along with Korean ${ }^{11}$ and Mongolian dentists, ${ }^{20}$ tend to underestimate the role of fluoride in caries prevention while in Finland, with a long history of caries prevention, dentists regard fluoride as an important cariespreventive measure. ${ }^{21}$ Accordingly, the important role of fluoride in caries prevention ${ }^{22,23}$ should be emphasised in dental curricula and continuing education programmes.

The present questions about dentists' knowledge of preventive dental care were planned to cover the very basic information and to be comparable with the previous similar studies among Korean ${ }^{11}$ and Mongolian dentists. ${ }^{20}$ Questioning about additional aspects of preventive dentistry, in more details, would be an interesting task regarding the further studies.

Dentists' attitudes towards prevention have received much attention in recent years especially regarding smoking cessation and oral cancer prevention. ${ }^{9,24-26}$ Overall, the dentists in this study showed positive attitudes towards preventive dental care especially regarding its benefits for the community. This is a positive indication that they are willing to become involved in preventive care. On the other hand, the dentists' answers indicate that they do not find preventive dental care to be economically beneficial and personally reputable. Similar findings have been reported in a study of British dentists. ${ }^{27}$ These attitudes among dentists may originate from such perceived barriers in their practice as inadequate reimbursement, ${ }^{28}$ time limitation because of high demand for curative care, ${ }^{29}$ and unwillingness of patients to pay for prevention. ${ }^{30}$

Attitudes are influenced by beliefs and values, personal needs, and behaviour. ${ }^{31,3}$ Accordingly, dentists' attitudes vary according to their background and professional factors. In the present study, however, these variations were significant only with respect to gender. More positive attitudes among women towards preventive dental care in this study, which is in line with the results of several other studies, ${ }^{32-35}$ may indicate their greater interest in preventive care compared to their male colleagues.

The sample subjects of this study were participants in two large annual dental meetings in Iran. Due to the lack of a reliable dentists' registry, a mail survey was out of the question, leaving the present method the only way to reach subjects for this survey. Dentists from all parts of the country take part in such meetings in order to collect credits toward the renewal of their practice license, to refresh their knowledge of various aspects of dentistry, and to visit the most comprehensive dental exhibitions. The current data on respondents' background are in line with the FDI data on Iranian dentists, ${ }^{36}$ thus allowing the present sample to be considered fairly representative of Iranian dentists. However, as is usually a natural characteristic of questionnaire surveys, some overrepresentation may occur because responding dentists tend to be more interested in the topics of the questionnaire and thus more confident and 
knowledgeable. Furthermore, due to the tendency of socially acceptable answering, preventivelyoriented attitudes found may not, however, relate to dentists' everyday professional activity.

\section{CONCLUSIONS}

Dentists' knowledge of and attitudes towards prevention should be improved and updated to enable and encourage them to provide their patients with preventive care.

\section{ACKNOWLEDGEMENTS}

We wish to thank all the dentists for participation and the Ministry of Health and Medical Education in Iran for cooperation. HG has received a grant from the Iran Centre for Dental Research, Shaheed Beheshti Dental School, for this research.

\section{REFERENCES}

1. Eijkman MAJ, de With C. Answers from dentists, dental hygienists and dental assistants to questions asked by patients concerning preventive dental matters. Community Dent Oral Epidemiol 1980;8:339-346.

2. McGlone P, Watt R, Sheiham A. Evidence-based dentistry: an overview of the challenges in changing professional practice. Br Dent $J$ 2001;190:636-639.

3. Brown G., Manogue M. and Rohlin M. Assessing attitudes in dental education: is it worthwile? Br Dent $J$ 2002;193:703707.

4. Petersson HG, Bratthall D. The caries decline: a review of reviews. Eur J Oral Sci 1996;104:436-443.

5. Eklund SA. Changing treatment patterns. J Amer Dent Assoc 1999;130:1707-1712.

6. Petersen PE, Estupinan-Day S, Ndiaye C. WHO's action for continuous improvement in oral health. Bull World Health Organ 2005;83:642.

7. Gonzalez CD, Frazier PJ, Messer LB. Sealant knowledge and use by pediatric dentists: 1987 Minnesota survey. $J$ Dent Child 1988;55:434-440.

8. Allard RH. Tobacco and oral health: attitudes and opinions of European dentists; a report of the EU working group on tobacco and oral health. Int Dent J 2000;50:99-102.

9. Kujan O, Duxbury AJ, Glenny AM, Thakker NS, Sloan P. Opinions and attitudes of the UK's GDPs and specialists in oral surgery, oral medicine and surgical dentistry on oral cancer screening. Oral Dis 2006;12:194-199.

10. Lewis DW, Main PA. Ontario dentists' knowledge and beliefs about selected aspects of diagnosis, prevention and restorative dentistry. J Can Dent Assoc 1996;62:337-344.

11. Moon H, Paik D, Horowitz AM, Kim J. National survey of
Korean dentists' knowledge and opinions: dental caries etiology and prevention. J Public Health Dent 1998;58:5156.

12. Ghasemi H, Murtomaa H, Torabzadeh H, Vehkalahti MM. Determinants of oral health behaviour among Iranian dentists. Int Dent J 2007;57:237-242.

13. Fejerskov 0, Kidd EAM. Dental Caries: The Disease and its Clinical Management, Oxford, Blackwell Munksgaard 2003, pp 116-213.

14. Tseveenjav B. Preventive dentistry in Mongolia. Academic dissertation, University of Helsinki, 2004.

15. Rosenberg HM, Thompson NL. Attitudes toward women dental students among male dental students and male dental faculty members. J Dent Educ 1976;40:676-680.

16. Bratthall D, Hansel-Petersson G, Sundberg H. Reasons for the caries decline: What do the experts believe? Eur J Oral Sci 1996;104:416-422.

17. Ellwood R, Fejerskov 0 (eds). Clinical use of fluoride. In: Fejereskov 0, Kidd EAM. Dental caries: the disease and its clinical management. London, Blackwell Munksgaard 2003, pp 212-213.

18. Khami MR, Virtanen JI, Jafarian M, Murtomaa H. Oral health behaviour and its determinants amongst Iranian dental students. Eur J Dent Educ 2007;11:42-47.

19. Khami MR, Jafarian M, Murtomaa H, Virtanen JI. Knowledge and attitude of Iranian dental school educators towards prevention. Oral Health Prev Dent 2007;5:(In Press).

20. Tseveenjav B, Vehkalahti M, Murtomaa H. Oral health and its determinants among Mongolian dentists. Acta Odontol Scand 2004;62:1-6.

21. Vehkalahti MM, Widström E. Teaching received in caries prevention and perceived need for Best Practice Guidelines among recent graduates in Finland. Eur $J$ Dent Educ 2004;8:7-11

22. Marinho VC, Higgins JP, Sheiham A, Logan S. Fluoride toothpastes for preventing dental caries in children and adolescents. Cochrane Database Syst Rev 2003;1: CD002278.

23. Twetman S, Axelsson S, Dahlgren H, Holm AK, Kallestal C, Lagerlof F, Lingstrom P, Mejare I, Nordenram G, Norlund A, Petersson LG, Soder B. Caries-preventive effect of fluoride toothpaste: a systematic review. Acta Odontol Scand 2003;61:347-355.

24. Stacey F, Heasman PA, Heasman L, Hepburn S, McCracken GI, Preshaw PM. Smoking cessation as a dental intervention-views of the profession. Br Dent J 2006;201:109-113.

25. Gajendra S, Cruz GD, Kumar JV. Oral cancer prevention and early detection: knowledge, practices, and opinions of oral health care providers in New York State. J Cancer Educ 
2006;21:157-162

26. Lehew CW, Kaste LM. Oral cancer prevention and early detection knowledge and practices of Illinois dentists--a brief communication. J Public Health Dent 2007;67:89-93.

27. Holloway PJ, Clarkson JE. Cost: benefit of prevention in practice. Int Dent J 1994;44:317-322.

28. Pine $C M$, Adair PM, Burnside G, Nicoll AD, Gillett A, Borges-Yanez SA, Broukal Z, Brown J, Declerck D, Ping FX, Gugushe T, Hunsrisakhun J, Lo EC, Naidoo S, Nyandindi U, Poulsen VJ, Razanamihaja N, Splieth C, Sutton BK, Soo TC, Whelton $\mathrm{H}$ : Barriers to the treatment of childhood caries perceived by dentists working in different countries. Community Dent Health 2004;21:Suppl 1:112-120.

29. Tseveenjav B, Vehkalahti MM, Murtomaa H. Barriers to the provision of oral health education among Mongolian dentists. Oral Health Prev Dent 2005;3:183-188.

30. Tomlinson $P$, Treasure E: Provision of prevention to adults in NHS dental practices and attitudes to prevention. $\mathrm{Br}$ Dent $J$ 2006;200:393-397.

31. Schafer RB, Tait JL. A guide for understanding attitudes and attitude change. Bulletin of the North Central Region Extension Sociology Committee, North Central Region Extension Publication 138, 1986.

32. Murtomaa H, Haavio-Mannila E, Kandolin I. Burnout and its causes in Finnish dentists. Community Dent Oral Epidemiol 1990;18:208-212.

33. Kärkkäinen S. Karieksen ehkäisykäytäntö Suomessa 1990luvun alussa. Thesis, English abstract and summary. Oulu, Acta Universitatis Ouluensis, 1997, D434.

34. Murray JJ. Better opportunities for women dentists: a review of the contribution of women dentists in the workforce. Br Dent J 2002;192:191-196.

35. Brennan DS, Spencer AJ. The role of dentist, practice and patient factors in the provision of dental services. Community Dent Oral Epidemiol 2005;33:181-195.

36. FDI (2000). Dental personnel in Iran. Available at: www.fdiworldental.org/resources/assets/facts_and_ figures/2000/IRAN.PDF 